\title{
Glucagon-like peptide-1 receptor overexpression in cancer and its impact on clinical applications
}

\author{
Meike Körner ${ }^{1}$, Emanuel Christ ${ }^{2}$, Damian Wild ${ }^{3}$ and Jean Claude Reubi ${ }^{1}$ * \\ 'Division of Cell Biology and Experimental Research, Institute of Pathology, University of Berne, Berne, Switzerland \\ ${ }^{2}$ Division of Endocrinology, Diabetology and Clinical Nutrition, University Hospital of Berne, Inselspital, Berne, Switzerland \\ ${ }^{3}$ Division of Nuclear Medicine, Department of Radiology, University Basel Hospital, Basel, Switzerland
}

\section{Edited by:}

Jae Young Seong, Korea University, South Korea

\section{Reviewed by:}

Jong-lk Hwang, Korea University, South Korea

Billy K. Chow, University of Hong

Kong, China

\section{*Correspondence:}

Jean Claude Reubi, Division of Cell Biology and Experimental Research, Institute of Pathology, University of Berne, Murtenstrasse 31, $\mathrm{CH}-3010$ Berne, Switzerland. e-mail: reubi@pathology.unibe.ch
Peptide hormones of the glucagon-like peptide (GLP) family play an increasing clinical role, such as GLP-1 in diabetes therapy. Moreover, GLP receptors are overexpressed in various human tumor types and therefore represent molecular targets for important clinical applications. In particular, virtually all benign insulinomas highly overexpress GLP-1 receptors (GLP-1R). Targeting GLP-1R with the stable GLP-1 analogs ${ }^{111}$ In-DOTA/DPTA-exendin-4 offers a new approach to successfully localize these small tumors. This non-invasive technique has the potential to replace the invasive localization of insulinomas by selective arterial stimulation and venous sampling. Malignant insulinomas, in contrast to their benign counterparts, express GLP-1R in only one-third of the cases, while they more often express the somatostatin type 2 receptors. Importantly, one of the two receptors appears to be always expressed in malignant insulinomas. The GLP-1R overexpression in selected cancers is worth to be kept in mind with regard to the increasing use of GLP-1 analogs for diabetes therapy. While the functional role of GLP-1R in neoplasia is not known yet, it may be safe to monitor patients undergoing GLP-1 therapy carefully.

Keywords: glucagon-like peptide-1, glucagon-like peptide-1 receptor, insulinoma, ${ }^{111}$ In-DOTA/DPTA-exendin-4

\section{INTRODUCTION}

G protein-coupled peptide hormone receptors play an increasing role as tumor targets in cancer medicine (Reubi, 2003). The underlying molecular basis is primarily an overexpression of a specific peptide receptor on tumor cells, irrespective of receptor functions. This overexpression allows a receptor-targeted scintigraphic imaging and radiotherapy of tumors with adequate radiolabeled peptide analogs (Reubi, 2003). Historically, the somatostatin receptors were the first receptors identified for these purposes (Reubi, 2003). They are expressed in high incidence and at high levels in gastroenteropancreatic neuroendocrine tumors (Reubi, 2003). Somatostatin receptor scintigraphy using the somatostatin analog octreotide (OctreoScan $\left.{ }^{\circledR}\right)$ represents nowadays a standard imaging procedure for patients with gut neuroendocrine tumors, while PET/CT with ${ }^{68} \mathrm{Ga}$-labeled somatostatin analogs turns out to be even superior to OctreoScan ${ }^{\circledR}$ (Gabriel et al., 2007). Furthermore, results from clinical studies performing somatostatin receptor-mediated radionuclide therapy are encouraging (Kwekkeboom et al., 2008; Imhof et al., 2011).

The clinical success of somatostatin receptor targeting of gut neuroendocrine tumors has stimulated the search for other peptide receptors suitable for similar applications. A promising candidate is the glucagon-like peptide 1 (GLP-1) receptor (GLP1R). This receptor has been cloned almost 20 years ago (Thorens et al., 1993). It is a member of the class $2 \mathrm{G}$ protein-coupled receptor family (Gros et al., 1993; Nauck, 2009). Only a single GLP-1R has been identified so far, which is structurally identical in all tissues (Thorens et al., 1993). Receptor activation upon agonist binding stimulates adenylate cyclase and phospholipase C, with subsequent activation of protein kinase A and C, respectively (Thorens et al., 1993).

Physiologically, the GLP-1R is expressed mainly in the alimentary tract, particularly in the pancreatic islet cells (Wei and Mojsov, 1995) where it mediates the actions of GLP-1 released from the small intestines in response to food intake. GLP- 1 is considered to be one of the most important glucose-dependent insulin secretagogues (Nauck, 2009). Specifically, it stimulates glucosedependent insulin synthesis and secretion, inhibits glucagon secretion, decreases $\beta$-cell apoptosis and increases differentiation of $\beta$-cell precursor cells in the pancreas as well as inhibits gastric emptying and appetite at the hypothalamic level (Nauck et al., 2009). Exploiting GLP-1 pathways therefore represents an ideal therapeutic approach for patients with type 2 diabetes, as this interferes with the main pathophysiological mechanisms of the disease (Nauck et al., 2009). Indeed, synthetic GLP-1 analogs are FDA- and EMEA-approved for the treatment of type 2 diabetes (Nauck et al., 2009).

The GLP-1R is of clinical interest not only due to its physiologic expression and functions in pancreatic islet cells and its potential in diabetes therapy, but also because of its possible role in cancer. Indeed, 10 years ago, the GLP-1R was found to be expressed in insulin-producing islet cell tumors, i.e., insulinomas (Reubi and Waser, 2003). This discovery lead to an extensive evaluation of the potential of the GLP-1R for targeted tumor imaging and therapy analogous to somatostatin receptor targeting of gut neuroendocrine tumors. This evaluation included the characterization of human tumors and normal tissues for their GLP-1R expression, since an important prerequisite for a successful peptide receptor 
targeting of tumors is a high receptor expression in tumors, but a low receptor expression in normal background tissues. Further activities included the development of adequate radiolabeled GLP-1 analogs, testing of such analogs in in vivo animal models and application of selected suitable candidate analogs to tumor patients in preliminary clinical studies. This review summarizes the knowledge on the in vitro and in vivo basis of GLP-1 receptor targeting of tumors accumulated in the last decade.

\section{GLP-1R IN TUMORS}

The GLP-1R expression has been systematically assessed in a broad spectrum of original human tumor tissues using in vitro receptor autoradiography (Reubi and Waser, 2003; Korner et al., 2007; Waser et al., 2011). The GLP-1R was thus identified in specific endocrine, embryonal, and brain tumors, but virtually not in carcinomas (Table 1). The most striking GLP-1R expression was found in insulinoma. This is an endocrine tumor of the pancreatic islet cells with mostly benign biological behavior, but characterized clinically by severe symptoms of hyperinsulinism due to insulin secretion. Benign insulinomas expressed GLP-1Rs in very high incidence ( $>90 \%$ ) and extremely high density (Reubi

Table 1 | GLP-1R expressing human tumors: receptor incidences and densities.

\begin{tabular}{lll}
\hline Tumor type & GLP-1R incidence & GLP-1R density* \\
\hline Endocrine tumors & & \\
Benign insulinomas & $25 / 27(93 \%)$ & 8,133 \\
Malignant insulinomas & $4 / 11(36 \%)$ & $8,508^{\dagger}$ \\
Gastrinomas & $10 / 10(100 \%)$ & 2,461 \\
Glucagonomas & $2 / 4(50 \%)$ & 910 \\
VIPomas & $1 / 4(25 \%)$ & 3,028 \\
lleal carcinoids & $8 / 27(30 \%)$ & 1,027 \\
Bronchial carcinoid tumors & $11 / 29(38 \%)$ & 2,456 \\
Pheochromocytomas & $12 / 20(60 \%)$ & 3,970 \\
Paragangliomas & $5 / 18(28 \%)$ & 1,353 \\
Medullary thyroid carcinomas & $5 / 18(28 \%)$ & 1,326 \\
Embryonal tumors & & \\
Medulloblastomas & $3 / 12(25 \%)$ & 1,246 \\
Nephroblastomas & $2 / 9(22 \%)$ & 421 \\
Neuroblastomas & $3 / 16(19 \%)$ & 932 \\
Brain tumors & & 1,283 \\
Meningiomas & $7 / 20(35 \%)$ & 989 \\
Astrocytomas & $4 / 16(25 \%)$ & 1,069 \\
Glioblastomas & $2 / 21(9 \%)$ & 790 \\
Ependymomas & $1 / 6(16 \%)$ & 1,075 \\
Carcinomas & & \\
Ovarian adenocarcinomas & $2 / 12(16 \%)$ & 688 \\
Prostate adenocarcinomas & $1 / 20(5 \%)$ & \\
\hline & & \\
\hline dpming tissue & & \\
\hline & & \\
\hline
\end{tabular}

${ }^{*} d p m / m g$ tissue.

${ }^{\dagger}$ Mean value of two tumors tested with in vitro GLP-1R autoradiography. and Waser, 2003; Table 1; Figure 1). In fact, no other peptide receptor has been found to exhibit such high expression levels in this tumor type (Reubi and Waser, 2003). On the contrary, malignant, metastasizing insulinomas expressed GLP-1Rs significantly less frequently. High GLP-1R levels were found in only 36\% malignant insulinomas (Wild et al., 2011). In insulinoma cells, the GLP-1R may represent a mediator of insulin secretion: in a model of GLP-1R transfected insulinoma cells, glucose-mediated insulin release was increased compared to control cells, in parallel with an increase of the intracellular second messenger of the GLP-1R (cAMP; Montrose-Rafizadeh et al., 1997).

Also several other functioning endocrine tumors of the pancreas expressed GLP-1Rs, in particular gastrinomas, however in lower amounts compared with insulinomas (Table 1; Reubi and Waser, 2003). Moreover, GLP-1Rs were discovered in a number of extrapancreatic endocrine tumors, including ileal carcinoids, pheochromocytomas, paragangliomas, bronchial carcinoid tumors, and medullary thyroid carcinomas, while they were not identified in pituitary adenomas or adrenal cortical tumors (Korner et al., 2007). Pheochromocytomas are of particular clinical interest due to their high GLP-1R expression levels (Table 1). Furthermore, medullary thyroid carcinomas are noteworthy because of important species differences in their GLP-1R expression. In rats, virtually all medullary thyroid carcinomas expressed GLP-1Rs in high amounts (Waser et al., 2011), while in humans only $28 \%$ expressed GLP-1R at low density levels (Table 1).

Lower GLP-1R expression levels were found in embryonal tumors, including medulloblastoma, nephroblastoma, and neuroblastoma (Table 1). They showed GLP-1Rs in low density in 15-25\% of the tumors (Korner et al., 2007). Similarly, tumors of the nervous system such as meningiomas and astrocytomas demonstrated an incidence of GLP-1Rs between 25 and 35\%, whereas glioblastomas and ependymomas expressed GLP-1Rs in 9-16\% (Table 1; Korner et al., 2007). Schwannomas were devoid of GLP-1Rs (Korner et al., 2007).

Conversely, carcinomas exhibited a very low or no GLP-1R expression. Only ovarian and prostate carcinomas rarely showed GLP-1R at low levels, while breast, colorectal, gastric, pancreatic, hepatocellular, and cholangiocellular as well as lung carcinomas (non-small and small cell carcinomas) were negative for GLP-1R (Korner et al., 2007). Likewise, non-Hodgkin lymphomas did not express GLP-1R (Korner et al., 2007).

Among all GLP-1R expressing tumor types, insulinomas are at present of highest clinical interest for an in vivo targeting in patients, based on several considerations. First, insulinomas exhibit particularly high GLP-1R expression levels with respect to both incidence and density. Second, benign insulinomas, in contrast to most other gastroenteropancreatic neuroendocrine tumors, show relatively low expression levels of somatostatin receptors. Consequently, OctreoScan ${ }^{\circledR}$ is not a reliable tool to detect these tumors (Plockinger et al., 2004). Third, the exact intraoperative localization of insulinomas is critical in order to minimize the surgical intervention (Rostambeigi and Thompson, 2009). This is, however, difficult due to the small size of benign insulinomas (usually 10-20 mm). Conventional radiological procedures (endosonography, MR-, and CT-imaging) are not always 

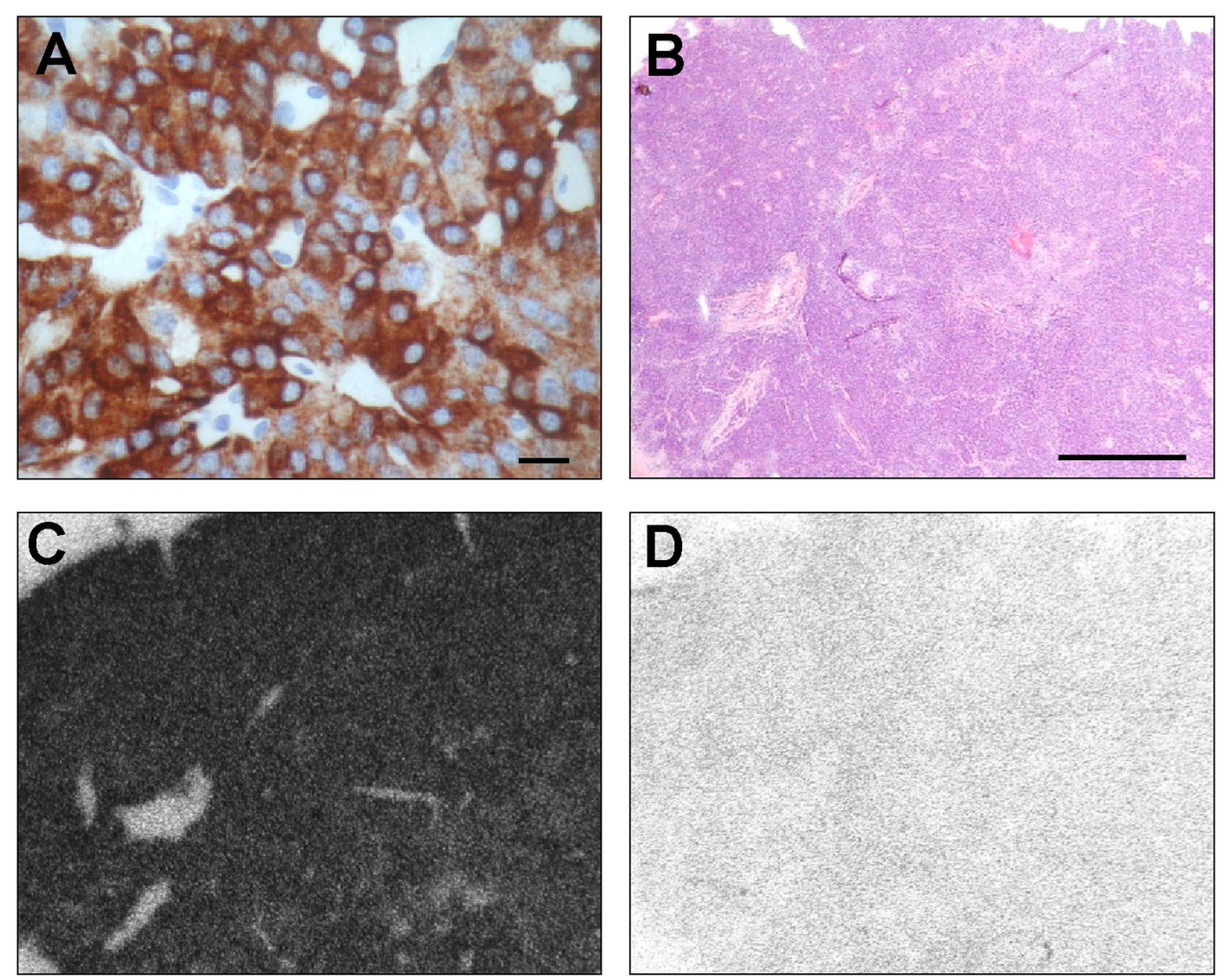

FIGURE 1 | Hormone and receptor determinations in vitro in a benign insulinoma. (A) Immunohistochemistry for insulin showing strongly labeled tumor cells. Bar $=0.01 \mathrm{~mm}$. (B-D) In vitro GLP-1R autoradiography on consecutive insulinoma tissue sections.

(B) Hematoxylin \& eosin (H\&E) staining showing the tumor tissue.
Bar $=1 \mathrm{~mm}$. (C) Autoradiogram showing total binding of ${ }^{125} \mathrm{I}-\mathrm{GLP}-1$ (7-36) amide. The entire tumor is strongly positive. (D) Autoradiogram showing non-specific binding of ${ }^{125}$ I-GLP-1(7-36) amide in the presence of $100 \mathrm{nM}$ cold GLP1(7-36) amide. Reprinted from Christ et al. (2010), with permission from Elsevier. successful in localizing insulinomas (Chatziioannou et al., 2001). Moreover, $\left[{ }^{18} \mathrm{~F}\right]$ DOPA PET shows at present controversial results, with sensitivities ranging between 17 and 90\% (Kauhanen et al., 2007; Tessonnier et al., 2010). Although selective arterial stimulation and venous sampling is a reliable intraoperative tool to detect insulinomas in experienced institutions (Wiesli et al., 2004), it is an invasive procedure with the associated risks. Moreover, this procedure identifies only the region of the pancreas - depending on the vasculature - where the insulinoma should be located and not the tumor itself (Wiesli et al., 2004).

\section{GLP-1R IN NON-NEOPLASTIC TISSUES}

The GLP-1R expression was similarly characterized in human normal tissues. It has been found in the pancreatic islets and acini, stomach, duodenal Brunner's gland, small and large intestinal myenteric plexus, lung and kidney vasculature, breast parenchyma, heart, brainstem, hypothalamus, neurohypophysis, and meninges (Wei and Mojsov, 1995; Korner et al., 2007). In vitro receptor autoradiography revealed that GLP-1R levels were highest in the neurohypophysis, followed by Brunner's glands, meninges, and pancreatic islets (Korner etal., 2007). Of practical importance, with the exception of Brunner's glands, the different tissues in the pancreatic area (i.e., pancreas islets and acini, intestines, and kidney) exhibit far lower GLP-1R density levels than insulinomas.
This results in a high tumor-to-background ratio in GLP-1R density levels for insulinomas, which is an important prerequisite for a GLP-1R-targeted scintigraphic imaging of insulinomas.

Prominent species differences in the physiological GLP-1R expression between humans and rodents are noteworthy. Indeed, autoradiography experiments indicate that GLP-1R density levels are considerably higher in the lungs of rats and mice than of humans (Korner et al., 2007). This has to be considered when interpreting results of in vivo testing of GLP-1R targeting in rodent models. Likewise, the GLP-1R expression in the thyroid gland is substantial in rodents, but virtually absent in humans (Korner et al., 2007). In rodent thyroids, GLP-1Rs are located in the medullary C-cells. Of interest, treatment with GLP-1 analogs in rats is known to occasionally lead to thyroid C-cell hyperplasia and medullary thyroid carcinoma, whereas in humans there is so far no evidence of such complications. It can be speculated whether the species differences in the GLP-1R density expression in the precursor cells of these tumors, the medullary C-cells, contribute to these controversial findings (Waser et al., 2011).

\section{RADIOLABELED GLP-1 ANALOGS}

In general, radioactively labeled peptide analogs represent pharmaceuticals with favorable characteristics. Due to their small size, they show fast diffusion and rapid blood clearance and lack 
immunogenicity. Moreover, radiopeptides exhibit only rare side effects (Reubi, 2003). In addition, radiolabeling is easily feasible, preferably after attaching a chelator to the peptide (Reubi and Maecke, 2008). However, since peptides are physiologically degraded within minutes in the human blood by potent peptidases such as dipeptidyl-peptidase-4 (DPP-4; Baggio and Drucker, 2007), stable peptide analogs have to be used instead in clinical applications. As for GLP-1, a naturally occurring stable analog exists, namely exendin-4, which is a component of the Gila monster venom. It shares 53\% homology with GLP-1 and similarly binds to GLP-1Rs, but is resistant to DPP-4 cleavage (Nauck, 2009). Exendin-4 is, therefore, a good candidate for the development of radiolabeled GLP-1R ligands.

The first radiopeptides tested for in vivo GLP-1R targeting were ${ }^{125}$ I-labeled GLP-1 and the GLP-1 analog exendin-3 (Gotthardt et al., 2002). However, the low peptide stability of GLP-1 and the low efficiency of radio-iodination of exendin-3 limited their clinical use. Further testing resulted in the development of ${ }^{111}$ In-labeled exendin-4 (Wild et al., 2006): exendin-4 was coupled via the Lys side chain to a chelator (DOTA, tetraazacyclododecane tetraacetic acid or DTPA, diethylenetriaminepentaacetic acid) using a spacer (Ahx, aminohexanoic acid) and then labeled with ${ }^{111}$ In. This radiopeptide was subsequently extensively tested in vitro and in vivo in insulinoma models and applied to insulinoma patients (see below). Lately, several studies have been published that describe GLP-1R ligands suitable for PET/CT imaging, such as ${ }^{68} \mathrm{Ga}-,{ }^{64} \mathrm{Cu}-$, or ${ }^{18} \mathrm{~F}$-labeled exendin-4, or for SPECT/CT imaging like ${ }^{99 \mathrm{~m}}$ Tc-labeled exendin-4 (Brom et al., 2010; Wild et al., 2010; Wu et al., 2011; Kiesewetter et al., 2012). These novel radiopeptides have not yet been tested in insulinoma patients.

\section{GLP-1R TARGETING IN ANIMAL MODELS}

Initially, GLP-1R targeting was performed in the rat insulinoma cell line RINm5F and in a rat insulinoma animal model (NEDH rats) using ${ }^{125}$ I-labeled GLP-1 and exendin-3 (Gotthardt et al., 2002). Specific uptake was detected in the cell and animal models. This provided the proof of principle for GLP-1R targeting of insulinoma (Gotthardt et al., 2002).

Follow-up experiments were carried out in the Rip1tag2 mouse model with ${ }^{111}$ In-DTPA-exendin- 4 . These transgenic mice develop tumors of the pancreatic $\beta$-cells in a reproducible multistage fashion (Hanahan, 1985) and, therefore, represent an ideal model to study GLP-1R targeting in vivo and in vitro. Using GLP$1 \mathrm{R}$ multipinhole SPECT/MRI and SPECT/CT, in vivo GLP-1R imaging was performed in these animals following administration of ${ }^{111}$ In-DTPA-exendin-4 (Wild et al., 2006). In parallel, GLP-1R autoradiography of the tumors was carried out in vitro. Finally, biodistribution and pharmacokinetics as well as internalization and cellular retention of ${ }^{111}$ In-DTPA-exendin-4 were measured in vitro (Wild et al., 2006).

This preclinical study showed the following main findings: First, the GLP-1R density in the tumors was extremely high, resulting in a remarkably high uptake of ${ }^{111}$ In-DTPA-exendin4 (287 $\pm 62 \% \mathrm{IA} / \mathrm{g}$ tissue) already $4 \mathrm{~h}$ after injection. Second, excellent visualization of tumors as small as $1 \mathrm{~mm}$ by pinhole SPECT/MRI and SPECT/CT was demonstrated. Third, the tumor-to-background ratio was very high (between 13.6 and 299), substantiating the high potential of this radiopeptide to specifically localize GLP-1R positive lesions within the pancreas. Lastly, in vitro studies in the cells derived from the tumor model demonstrated a specific internalization of ${ }^{111}$ In-DTPA-exendin-4, and biochemical investigations confirmed the high metabolic stability of the radiopeptide in the tumor cells as well as in the serum.

The same Rip1tag2 mouse model also provided preliminary data on GLP-1R-targeted therapy of insulinoma. Mice were injected with different doses of ${ }^{111}$ In-DTPA-exendin-4 (1.1, 5.6, and $28 \mathrm{MBq}$ ) and sacrificed 7 days after injection. Most impressively, a single injection lead to a reduction in tumor volume of up to $94 \%$ in a dose-dependent manner without significant acute organ toxicity. Histological examination revealed that the decrease in tumor mass was mainly due to an increase in tumor cell apoptosis and decreased proliferation (Wicki et al., 2007).

\section{GLP-1R TARGETING IN HUMANS}

The first patient who underwent GLP-1R scintigraphy suffered from severe endogenous hyperinsulinemic hypoglycemia with non-convulsive seizures. MRI, CT scan, and endosonography did not detect any suspicious lesion. However, GLP-1R scintigraphy revealed an increased extrapancreatic uptake in the mesentery supplied by the anterior mesentery artery. Selective arterial stimulation and venous sampling correctly indicated the vascular territory, but since this patient had an ectopic insulinoma, the results of the invasive investigation without GLP-1R imaging would have been misleading for the surgical strategy (Wild et al., 2008).

In a proof of principle study, ${ }^{111}$ In-DOTA-exendin-4 was prospectively administered to a total of six patients (Christ et al., 2009). All of them presented with neuroglycopenic symptoms lasting for 4-26 months. Biochemical evaluation during a fasting test revealed endogenous hyperinsulinemic hypoglycemia in all patients.

Conventional imaging (CT or MRI) reliably detected the insulinoma in only two patients, whereas endosonography identified a possible lesion in four patients, in keeping with data in the literature (McAuley et al., 2005). In three patients, selective arterial stimulation and venous sampling was performed, with accurate localization in all (Christ et al., 2009). Remarkably, GLP1-R scintigraphy correctly detected the insulinoma in all six consecutive patients (Figure 2; Christ et al., 2009). Four patients underwent an enucleation of the insulinoma. In two patients, a Whipple procedure had to be performed due to the localization of the insulinoma. In all patients, a benign insulinoma was confirmed by histology. In vitro autoradiography studies showed GLP-1R densities in the range as previously described (between 2,600 to $>10,000 \mathrm{dpm} / \mathrm{mg}$ tissue; Reubi and Waser, 2003), but low levels of somatostatin receptor type 1 in 2 patients only (Christ et al., 2009). Importantly, within a time frame of 2-14 days after injection of ${ }^{111}$ In-DOTA-exendin-4, intraoperative utilization of a gamma probe was highly beneficial for the in situ localization of the insulinoma in all patients, resulting in a successful enucleation where possible (Christ et al., 2009).

Fortunately, background uptake over the whole body was low with the exceptions of the kidneys, which were strongly labeled due to renal excretion of the radioligand (Figure 2). In two 


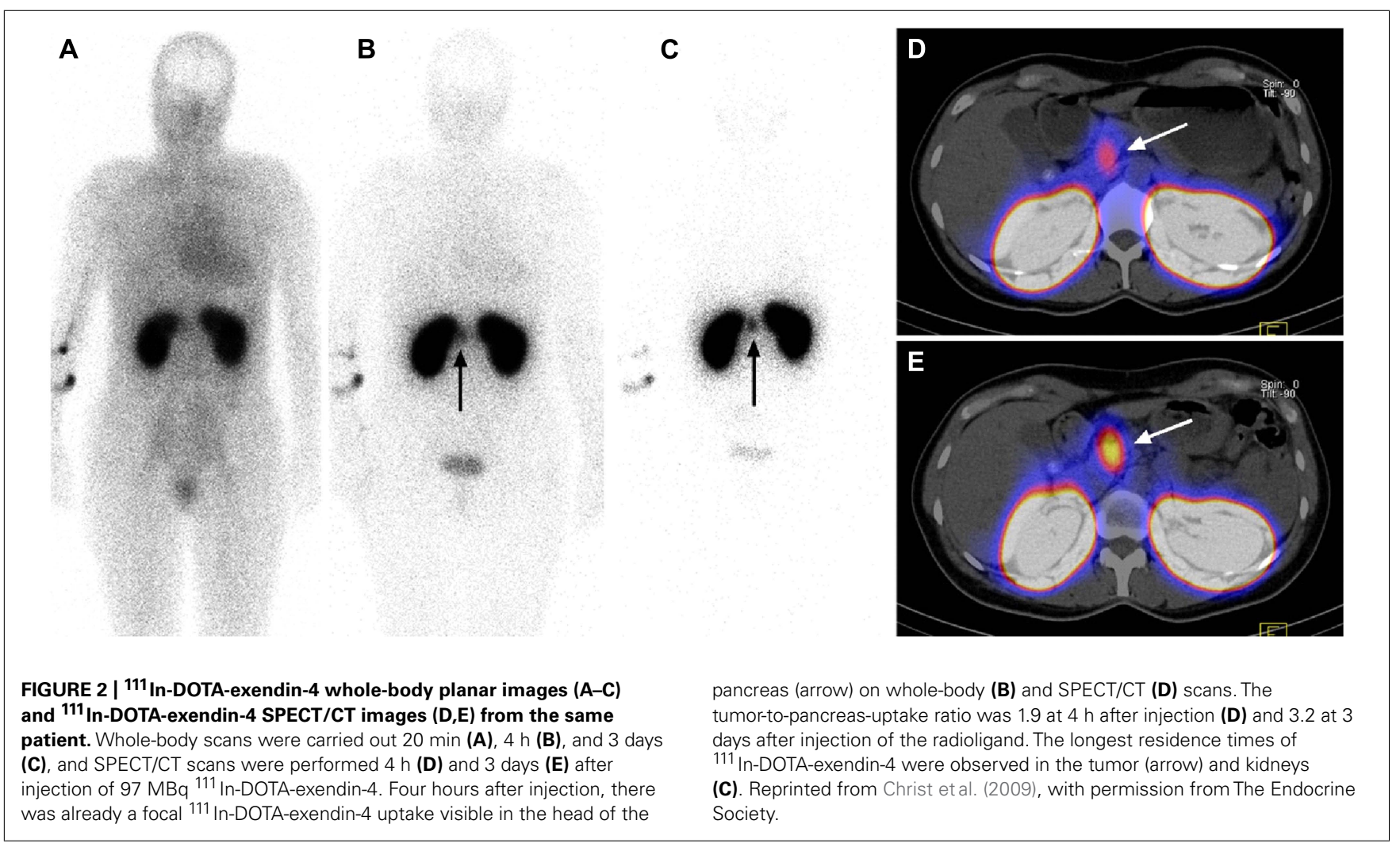

patients demarcation between tumors (maximal diameter of 9$11 \mathrm{~mm}$ ) and kidneys was only possible after late scans, indicating an improved tumor-to-kidney ratio with time, in keeping with the fact that the effective half-life of ${ }^{111}$ In-DOTA-exendin- 4 was longer in the tumor (38-64 h) than in the kidneys (31.2-31.8 h; Figure 2; Christ et al., 2009). This suggests that patients with negative early scans should have additional imaging 3-7 days after the injection.

In humans, ${ }^{111}$ In-DOTA-exendin- 4 was initially administered, but later replaced by ${ }^{111}$ In-DTPA-exendin- 4 due to the four times higher specific activity of the latter (Wild et al., 2009). A higher specific activity permits to reduce the amount of peptide (exendin4 ), thereby decreasing the occurrence of possible side effects. In addition, radiolabeling of DTPA-exendin- 4 can be performed at room temperature, whereas labeling of DOTA-exendin-4 has to be accomplished at high temperature $\left(95^{\circ} \mathrm{C}\right.$; Wild et al., 2006).

By now, data of a prospective, multicenter trial including 30 patients that underwent GLP-1R scanning are available. The inclusion criteria were proven endogenous hyperinsulinemic hypoglycemia and none or maximally one lesion on conventional imaging. Conventional imaging (CT, MRI) and endosonography - where available - was performed locally using a standard protocol. ${ }^{111}$ In-DTPA-exendin-4 was administered intravenously at a dose of 90-130 MBq over $2 \mathrm{~min}$. Whole-body planar images and SPECT/CT of the abdomen were performed at 4, 24 and in some patients between 72 and 96 up to $168 \mathrm{~h}$ post-injection, the most important time point being the scan $24 \mathrm{~h}$ after injection. Diagnosis was confirmed by histology after surgical removal (Christ et al., 2012).
Conventional imaging (MRI, CT, endosonography) was positive in 17 patients. ${ }^{111}$ In-DTPA/DOTA-exendin-4 SPECT/CT detected 23 true positive benign insulinomas and five additional positive lesions (one malignant insulinoma; two islet cell hyperplasias; two uncharacterized lesions). True negative tests were detected in two patients (one malignant insulinoma; one islet cell hyperplasia). Malignant insulinomas were diagnosed based on the histological finding of a positive lymph node, not detected on conventional imaging preoperatively. There was no false negative result. Sensitivity was $100 \%$ and the positive predictive value was $82 \%$ (Christ et al., 2012). These findings are encouraging and suggest that in vivo GLP-1R imaging defines a new noninvasive diagnostic approach to successfully localize small benign insulinomas.

About $90 \%$ of insulinomas are benign and only $10 \%$ of patients present with malignant disease usually characterized by liver metastasis (Plockinger et al., 2004). Anecdotal evidence suggests that malignant insulinomas exhibit more often somatostatin receptors type 2 than benign ones and can, therefore, be visualized by OctreoScan ${ }^{\circledR}$ (Plockinger et al., 2004). A more extensive study with data from 10 patients with malignant insulinoma showed that somatostatin receptors type 2 were expressed in seven patients, whereas GLP-1R were present in four patients, and both receptors in only one patient (Wild et al., 2011). Importantly, one of the two imaging methods appears always to be positive in a malignant type of insulinoma (Wild et al., 2011). The consequences of the respective receptor expression in an insulinoma with regard to biological behavior (malignant or benign course) remains to be established. 


\section{SIDE EFFECTS AND LIMITATIONS}

In humans, the injection of ${ }^{111}$ In-DOTA-exendin-4 and ${ }^{111}$ InDPTA-exendin-4 was well tolerated. Due to the small amount of exendin-4, the decrease in plasma glucose concentrations was only $1.4 \pm 0.7 \mathrm{mmol} / \mathrm{L}$ after $40 \mathrm{~min}$ (Christ et al., 2009). By regularly monitoring glucose levels, no severe hypoglycemic episode occurred. One patient experienced a short episode of vomiting only with ${ }^{111}$ In-DOTA-exendin-4. Otherwise, no further side effects were observed (Christ et al., 2009).

In two patients, there was focal ${ }^{111}$ In-DOTA-exendin-4 uptake in the proximal duodenum. This may be related to the presence of Brunnner's gland of the duodenum which, as previously mentioned, are known to contain GLP-1Rs in a significant density (Korner et al., 2007). Brunner's glands may become hyperplastic (Levine et al., 1995), as observed in particular in patients with chronic pancreatitis (Stolte et al., 1981). Such hyperplastic glands may possibly be detected by GLP-1R imaging.

A differential diagnosis of endogenous hyperinsulinemic hypoglycemia includes nesidioblastosis, also known as "noninsulinoma pancreatogenous hypoglycemia syndrome" in a clinical setting (Thompson et al., 2000). Histopathologically, this entity is defined as a diffuse hyperplasia of $\beta$-cells occurring usually in children (Yakovac et al., 1971). Recent evidence suggests that this pathology can also be demonstrated in adults, in particular after bypass surgery for morbid obesity (Service et al., 2005). In the previously mentioned series of patients (Christ et al., 2012), islet cell hyperplasia was diagnosed in three patients, two were positive on GLP-1R imaging and one was negative. Based on these preliminary data GLP-1R imaging does not appear to be an appropriate tool to diagnose or exclude islet cell hyperplasia. These findings are further supported by the recent evidence that the in vitro density of GLP-1R in pancreatic tissues of patients with nesidioblastosis after bypass surgery for morbid obesity is much lower than in benign insulinomas (Reubi et al., 2010).

\section{REFERENCES}

Baggio, L. L., and Drucker, D. J. (2007). Biology of incretins: GLP-1 and GIP. Gastroenterology 132, 2131-2157.

Brom, M., Oyen, W. J., Joosten, L., Gotthardt, M., and Boerman, O. C. (2010). (68)Ga-labelled exendin-3, a new agent for the detection of insulinomas with PET. Eur. J. Nucl. Med. Mol. Imaging 37, 1345-1355.

Chatziioannou, A., Kehagias, D., Mourikis, D., Antoniou, A., Limouris, G., Kaponis, A., et al. (2001). Imaging and localization of pancreatic insulinomas. Clin. Imaging 25, 275-283.

Christ, E., Forrer, F., Wild, D., Clerici, T., Braendle, M., Maecke, H., et al. (2012). Glucagon-like peptide 1 receptor (GLP-1R) imaging for the preoperative localization of benign insulinomas in 30 patients. Neuroendocrinology 96, 24-24.

Christ, E., Wild, D., Forrer, F., Brandle, M., Sahli, R., Clerici, T., et al. (2009). Glucagon-like peptide1 receptor imaging for localization of insulinomas. J. Clin. Endocrinol. Metab. 94, 4398-4405.

Christ, E., Wild, D., and Reubi, J. C. (2010). Glucagonlike peptide-1 receptor: an example of translational research in insulinomas: a review. Endocrinol. Metab. Clin. North Am. 39, 791-800.

Gabriel, M., Decristoforo, C., Kendler, D., Dobrozemsky, G., Heute, D., Uprimny, C., etal. (2007). 68GaDOTA-Tyr3-octreotide PET in neuroendocrine tumors: comparison with somatostatin receptor scintigraphy and CT. J. Nucl. Med. 48, 508-518.

Gotthardt, M., Fischer, M., Naeher, I., Holz, J. B., Jungclas, H., Fritsch, H. W., et al. (2002). Use of the incretin hormone glucagon-like peptide-1 (GLP-1) for the detection of insulinomas: initial experimental results. Eur. J. Nucl. Med. Mol. Imaging 29, 597-606.

Gros, L., Thorens, B., Bataille, D., and Kervran, A. (1993). Glucagon-like

Recently, ${ }^{18}$ F-DOPA-PET has successfully been used to detect nesidioblastosis and benign insulinoma (Kauhanen et al., 2007). Although ${ }^{18} \mathrm{~F}$-DOPA-PET may be helpful to diagnose nesidioblastosis, in benign insulinomas the tumor-to-background ratios are higher for ${ }^{111}$ In-DOTA-exendin-4 SPECT than for ${ }^{18} \mathrm{~F}$-DOPAPET (3.3 vs. 1.4), suggesting an increased sensitivity of targeting GLP-1Rs (Kauhanen et al., 2007; Christ et al., 2009) in benign insulinomas.

\section{SUMMARY AND CONCLUSION}

Because of the massive GLP-1R overexpression in selected gastrointestinal tumors, GLP-1 and GLP-1R play an increasing role in endocrine gastrointestinal tumor management. Targeting GLP$1 \mathrm{R}$ with ${ }^{111}$ In-DOTA-exendin- 4 or ${ }^{111}$ In-DPTA-exendin-4 offers a new approach that permits the successful localization of small benign insulinomas pre- and intraoperatively. Since virtually all benign insulinomas express GLP-1Rs and the preliminary clinical data are very encouraging, it is likely that this approach will affect the algorithm of pre- and intraoperative localization of suspected insulinoma.

In contrast to benign insulinomas, where the exact localization of the tumor is the main goal, the clinical challenge in malignant, metastasizing insulinomas is to define the extension of the disease and - if possible - offer a targeted therapy (peptide receptor radionuclide therapy, PRRT). Contrary to benign insulinomas, malignant insulinomas more often express sst2 receptors than GLP-1R. Importantly, one of the two receptors seems to be always expressed.

With regard to the increasing and successful use of GLP-1 analogs for diabetes therapy, it is worth keeping in mind that selected cancers can overexpress GLP-1R. While the functional role of these receptors in these tumors is not known yet, it may be safe to monitor patients with such tumors carefully during their GLP-1-analog-based diabetes therapy.

peptide-1-(7-36) amide, oxyntomodulin, and glucagon interact with a common receptor in a somatostatin-secreting cell line. Endocrinology 133, 631-638.

Hanahan, D. (1985). Heritable formation of pancreatic beta-cell tumours in transgenic mice expressing recombinant insulin/simian virus 40 oncogenes. Nature 315, 115-122.

Imhof, A., Brunner, P., Marincek, N., Briel, M., Schindler, C., Rasch, H., et al. (2011). Response, survival, and long-term toxicity after therapy with the radiolabeled somatostatin analogue [90Y-DOTA]-TOC in metastasized neuroendocrine cancers. J. Clin. Oncol. 29, 2416-2423.

Kauhanen, S., Seppanen, M., Minn, H., Gullichsen, R., Salonen, A., Alanen, K., et al. (2007). Fluorine-18-L-dihydroxyphenylalanine (18F-DOPA) positron emission tomography as a tool to localize an insulinoma or beta-cell hyperplasia in adult patients. J. Clin. Endocrinol. Metab. 92, 1237-1244.

Kiesewetter, D. O., Gao, H., Ma, Y., Niu, G., Quan, Q., Guo, N., et al. (2012). 18F-radiolabeled analogs of exendin-4 for PET imaging of GLP-1 in insulinoma. Eur. J. Nucl. Med. Mol. Imaging 39, 463-473.

Korner, M., Stockli, M., Waser, B., and Reubi, J. C. (2007). GLP-1 receptor expression in human tumors and human normal tissues: potential for in vivo targeting. J. Nucl. Med. 48, 736-743.

Kwekkeboom, D. J., de Herder, W. W., Kam, B. L., van Eijck, C. H., van Essen, M., Kooij, P. P., et al. (2008). Treatment with the radiolabeled somatostatin analog [177 Lu-DOTA 0,Tyr3] octreotate: toxicity, efficacy, and survival. J. Clin. Oncol. 26, 2124-2130.

Levine, J. A., Burgart, L. J., Batts, K. P., and Wang, K. K. (1995). Brunner's gland hamartomas: clinical presentation and pathological features of 
27 cases. Am. J. Gastroenterol. 90, 290-294.

McAuley, G., Delaney, H., Colville, J., Lyburn, I., Worsley, D., Govender, P., et al. (2005). Multimodality preoperative imaging of pancreatic insulinomas. Clin. Radiol. 60, 1039-1050.

Montrose-Rafizadeh, C., Wang, Y., Janczewski, A. M., Henderson, T. E., and Egan, J. M. (1997). Overexpression of glucagon-like peptide1 receptor in an insulin-secreting cell line enhances glucose responsiveness. Mol. Cell. Endocrinol. 130, 109-117.

Nauck, M. A. (2009). Unraveling the science of incretin biology. Eur. J. Intern. Med. 20, S303-S308.

Nauck, M. A., Vilsboll, T., Gallwitz, B., Garber, A., and Madsbad, S. (2009). Incretin-based therapies: viewpoints on the way to consensus. Diabetes Care 32, S223-S231.

Plockinger, U., Rindi, G., Arnold, R., Eriksson, B., Krenning, E. P., de Herder, W. W., et al. (2004). Guidelines for the diagnosis and treatment of neuroendocrine gastrointestinal tumours. Neuroendocrinology 80 , 394-424.

Reubi, J. C. (2003). Peptide receptors as molecular targets for cancer diagnosis and therapy. Endocr. Rev. 24, 389-427.

Reubi, J. C., and Maecke, H. R. (2008). Peptide-based probes for cancer imaging. J. Nucl. Med. 49, 17351738.

Reubi, J. C., Perren, A., Rehmann, R., Waser, B., Christ, E., Callery, M., et al. (2010). Glucagon-like peptide-1 (GLP-1) receptors are not overexpressed in pancreatic islets from patients with severe hyperinsulinaemic hypoglycaemia following gastric bypass. Diabetologia 53, 26412645.

Reubi, J. C., and Waser, B. (2003). Concomitant expression of several peptide receptors in neuroendocrine tumors as molecular basis for in vivo multireceptor tumor targeting. Eur. J. Nucl. Med. 30, 781-793.

Rostambeigi, N., and Thompson, G. B. (2009). What should be done in an operating room when an insulinoma cannot be found? Clin. Endocrinol. (Oxf.) 70, 512-515.

Service, G. J., Thompson, G. B., Service, F. J., Andrews, J. C., CollazoClavell, M. L., and Lloyd, R. V. (2005). Hyperinsulinemic hypoglycemia with nesidioblastosis after gastric-bypass surgery. N. Engl. J. Med. 353, 249-254.

Stolte, M., Schwabe, H., and Prestele, H. (1981). Relationship between diseases of the pancreas and hyperplasia of Brunner's glands. Virchows Arch. A Pathol. Anat. Histol. 394, 75-87.

Tessonnier, L., Sebag, F., Ghander, C., De Micco, C., Reynaud, R., Palazzo, F. F., et al. (2010). Limited value of 18F-F-DOPA PET to localize pancreatic insulin-secreting tumors in adults with hyperinsulinemic hypoglycemia. J. Clin. Endocrinol. Metab. 95, 303-307.

Thompson, G. B., Service, F. J., Andrews, J. C., Lloyd, R. V., Natt, N., van Heerden, J. A., et al. (2000). Noninsulinoma pancreatogenous hypoglycemia syndrome: an update in 10 surgically treated patients. Surgery 128, 937-944.

Thorens, B., Porret, A., Buhler, L., Deng, S. P., Morel, P., and Widmann, C. (1993). Cloning and functional expression of the human islet GLP-1 receptor. Demonstration that exendin-4 is an agonist and exendin(9-39) an antagonist of the receptor. Diabetes 42, 1678-1682.

Waser, B., Beetschen, K., Pellegata, N. S., and Reubi, J. C. (2011). Incretin receptors in non-neoplastic and neoplastic thyroid C cells in rodents and humans: relevance for incretin-based diabetes therapy. Neuroendocrinology 94, 291-301.

Wei, Y., and Mojsov, S. (1995) Tissue-specific expression of the human receptor for glucagon-like peptide-I: brain, heart and pancreatic forms have the same deduced amino acid sequences. FEBS Lett. 358 , 219-224.

Wicki, A., Wild, D., Storch, D., Seemayer, C., Gotthardt, M., Behe, M., et al. (2007). [Lys40(AhxDTPA-111In)NH2]-exendin-4 is a highly efficient radiotherapeutic for glucagon-like peptide-1 receptortargeted therapy for insulinoma. Clin. Cancer Res. 13, 3696-3705.

Wiesli, P., Brandle, M., Schmid, C., Krahenbuhl, L., Furrer, J., Keller, U., et al. (2004). Selective arterial calcium stimulation and hepatic venous sampling in the evaluation of hyperinsulinemic hypoglycemia: potential and limitations. J. Vasc. Interv. Radiol. 15, 1251-1256.

Wild, D., Behe, M., Wicki, A., Storch, D., Waser, B., Gotthardt, M., et al. (2006). [Lys40(AhxDTPA-111In)NH2] exendin-4, a very promising ligand for glucagon-like peptide-1 (GLP-1) receptor targeting. J. Nucl. Med. 47, 2025-2033.

Wild, D., Caplin, M., Christ, E., Forrer, F., Brändle, M., Seufert, J., et al. (2011). Glucagon-like peptide-1 vs. somatostatin receptor targeting in malignant insulinomas. J. Nucl. $\mathrm{Med}$. 52, 1073-1078.

Wild, D., Christ, E., Forrer, F., Reubi, J. C., Maecke, H., Ell, P. J., et al. (2009). 111In-DTPA-exendin4 SPECT/CT scans localize hardly detectable insulinomas. J. Nucl. Med. 50, 1937.

Wild, D., Mäcke, H., Christ, E., Gloor B., and Reubi, J. C. (2008). Glucagonlike peptide 1-receptor scans to localize occult insulinomas. N. Engl. J. Med. 359, 766-768.
Wild, D., Wicki, A., Mansi, R., Béhé, M., Keil, B., Bernhardt, P., et al. (2010). Exendin-4-based radiopharmaceuticals for glucagons-like peptide-1 (GLP-1) receptor PET/CT and SPECT/CT imaging. J. Nucl. Med. 51, 1059-1067.

Wu, Z., Todorov, I., Li, L., Bading, J. R., Li, Z., Nair, I., et al. (2011). In vivo imaging of transplanted islets with 64Cu-DO3A-VSCys40-exendin- 4 by targeting GLP-1 receptor. Bioconjug. Chem. 22, 15871594.

Yakovac, W. C., Baker, L., and Hummeler, K. (1971). Beta cell nesidioblastosis in idiopathic hypoglycemia of infancy. J. Pediatr. 79, 226-231.

Conflict of Interest Statement: The authors declare that the research was conducted in the absence of any commercial or financial relationships that could be construed as a potential conflict of interest.

Received: 01 October 2012; accepted: 23 November 2012; published online: 06 December 2012.

Citation: Körner M, Christ E, Wild D and Reubi JC (2012) Glucagon-like peptide1 receptor overexpression in cancer and its impact on clinical applications. Front. Endocrin. 3:158. doi: 10.3389/fendo. 2012.00158

This article was submitted to Frontiers in Neuroendocrine Science, a specialty of Frontiers in Endocrinology.

Copyright (c) 2012 Körner, Christ, Wild and Reubi. This is an open-access article distributed under the terms of the Creative Commons Attribution License, which permits use, distribution and reproduction in other forums, provided the original authors and source are credited and subject to any copyright notices concerning any third-party graphics etc. 